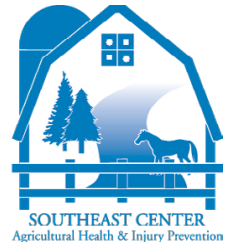

\title{
Southeast Center for Agricultural Health and Injury Prevention
}

February 2018

\section{What are our priorities?}

The Southeast Center for Agricultural Health and Injury Prevention (SCAHIP) is one of 11 agricultural research, education, and prevention centers funded by the National Institute for Occupational Safety and Health (NIOSH). Since its inception in 1992, the Southeast Center has built a consistent and evolving focus of research, education, and outreach to address emerging issues affecting the southeast region including:

- Reducing illness and injuries among logging and forestry workers.

- Reducing the number of tractor-related injuries and fatalities in farm communities in high-poverty areas across the southeast.

\section{What do we do?}

- Employ unique approaches that help students, teachers, parents, and other community members comprehend the individual and social costs of farm injury, in particular tractor overturns.

- Develop logging safety management programs to enhance safety and health management systems and improve the monitoring capabilities

\section{What have we accomplished?}

- Trained over 520 pre-career teachers and extension agents to recognize and understand occupational risks, hazards, injury prevention strategies, and the social costs of farm injuries using the latest educational technologies. These include interactive story simulations, interactive Excel ${ }^{\mathrm{TM}}$ Cost Tools, digital documentaries, an internet game template, and Virtual Tractor Inspection (VTI).

- Constructed and installed 120 Cost-effective Roll Over Protective Systems (CROPS) on unprotected tractors in agricultural mechanics classes. Involved nearly 500 students in 21 agri-

\section{What's next?}

- Develop a hazard surveillance collection tool mobile application for logging and implement it within a newly designed health and safety management program with 30 West Virginia logging companies.

- Partner with Silo Film, LLC, and its founder, film producer Samuel Goldberg, to distribute a short documentary inspired and informed by the harrowing story of two teenage boys who died from suffocation in a grain bin in Mount Carrol, III. in 2010.*

- Distribute a Discussion Guide along with the film across the southeast, resulting in the integration of life-saving grain handling and rescue information that will raise awareness and promote safety on the farm. of logging companies to increase the safety of their operations and reduce injuries.

- Provide essential education to address the critical shortage of agricultural occupational health and safety professionals in the southeast.

- Reach at-risk teens by integrating agricultural safety materials into school curricula.

\section{At-A-Glance}

The Southeast Center for Agricultural Health and Injury Prevention at the University of Kentucky conducts research, education, and outreach activities to reduce occupational illness and injury and improve the health and safety of agricultural, forestry and fish farming workers and their families in the southeastern United States.

SCAHIP serves the southeastern United States

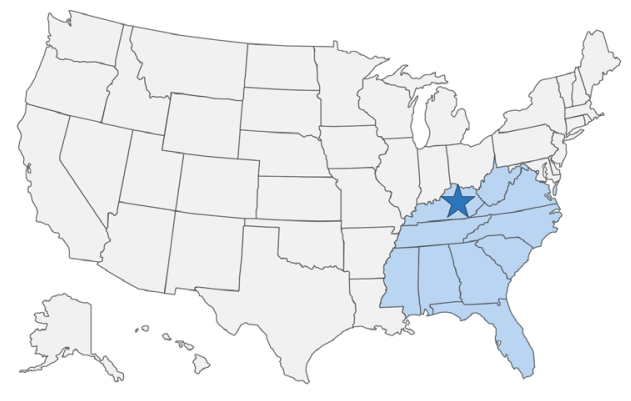

Logging tops U.S. civilian occupations with high fatal work injury rates (per 100, 000 fulltime equivalent workers) in 2015

cultural education programs in Kentucky, West Virginia, Virginia, North Carolina, South Carolina, Georgia, Alabama, Mississippi, Tennessee, and Missouri, protecting over 200 lives.

- Created a novel network to educate front-line nurse professionals to develop and deliver tailored evidence-based health care and health promotion to farm communities. Long-term, this project has the potential to impact the practice of 2.5 million registered nurses, 254,000 nurse students per year and the health of the agriculture populations they serve.

- Disseminate state-of-the-art curriculum suitable for high school and college level teaching and adult training within rural communities, including the interactive $3 \mathrm{D}$ video game to teach preventive safety measures, and the VTI.

- Conduct and support annual teacher training, online interactive teaching materials, community outreach, and project-based CROPS construction and installation combined with a social media crowd-funding campaign.

* Mention of any company or product does not constitute endorsement by the National Institute for Occupational Safety and Health (NIOSH), Centers for Disease Control and Prevention $(\mathrm{CDC})$

\section{Source: Bureau of Labor Statistics as cited in POLITICO, \\ Farmers, ranchers, other ag managers \\ Roofers 39.7 \\ Aircraft pilots and flight engineers \\ Fishers and related fishing workers \\ / / /www.politico.com/agenda/story/2017/04/the-most- dangerous-jobs-in-america-000395 \\ Number of $\square$ tractor-related farm deaths and total farm deaths by year}

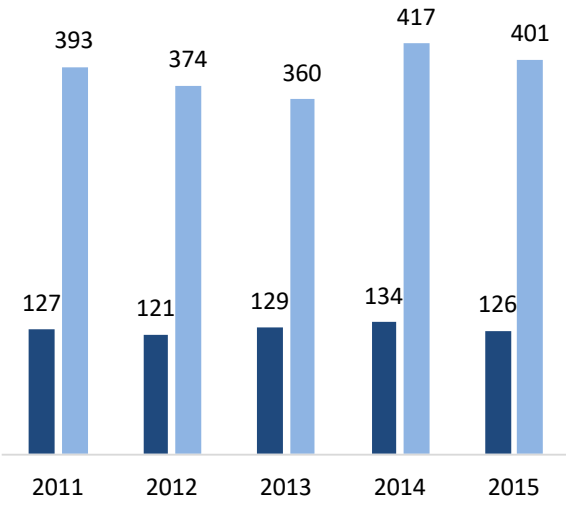

Source: Bureau of Labor Statistic 